\title{
Hybrid Carbon Fibers/Carbon Nanotubes Structures for Next Generation Polymeric Composites
}

\author{
M. Al-Haik,, ${ }^{1}$ C. C. Luhrs, ${ }^{1}$ M. M. Reda Taha, ${ }^{2}$ A. K. Roy, ${ }^{3}$ L. Dai, ${ }^{4}$ J. Phillips, ${ }^{5}$ and S. Doorn ${ }^{5}$ \\ ${ }^{1}$ Department of Mechanical Engineering, University of New Mexico, Albuquerque, NM 87131, USA \\ ${ }^{2}$ Department of Civil Engineering, University of New Mexico, Albuquerque, NM 87131, USA \\ ${ }^{3}$ AFRL/RXBT Thermal Sciences and Materials Branch, Wright-Patterson AFB, OH 45433, USA \\ ${ }^{4}$ Department of Chemical Engineering, Case Western Reserve University, Cleveland, OH 44106, USA \\ ${ }^{5}$ Los Alamos National Laboratory, Los Alamos, NM 87545, USA \\ Correspondence should be addressed to M. Al-Haik, alhaik@unm.edu
}

Received 2 July 2009; Revised 18 December 2009; Accepted 2 January 2010

Academic Editor: Quan Wang

Copyright ( $) 2010$ M. Al-Haik et al. This is an open access article distributed under the Creative Commons Attribution License, which permits unrestricted use, distribution, and reproduction in any medium, provided the original work is properly cited.

\begin{abstract}
Pitch-based carbon fibers are commonly used to produce polymeric carbon fiber structural composites. Several investigations have reported different methods for dispersing and subsequently aligning carbon nanotubes (CNTs) as a filler to reinforce polymer matrix. The significant difficulty in dispersing CNTs suggested the controlled-growth of CNTs on surfaces where they are needed. Here we compare between two techniques for depositing the catalyst iron used toward growing CNTs on pitch-based carbon fiber surfaces. Electrochemical deposition of iron using pulse voltametry is compared to DC magnetron iron sputtering. Carbon nanostructures growth was performed using a thermal CVD system. Characterization for comparison between both techniques was compared via SEM, TEM, and Raman spectroscopy analysis. It is shown that while both techniques were successful to grow CNTs on the carbon fiber surfaces, iron sputtering technique was capable of producing more uniform distribution of iron catalyst and thus multiwall carbon nanotubes (MWCNTs) compared to MWCNTs grown using the electrochemical deposition of iron.
\end{abstract}

\section{Introduction}

The attractive properties of carbon nanotubes [1] (CNTs) might be attributed to their unique and minimum defect nanostructure. Single wall carbon nanotubes (SWCNTs) possess exceptional mechanical $[2,3]$, thermal, and electric properties [4] compared to graphite, Kevlar, $\mathrm{SiC}$, and alumina fibers. The strength, elastic modulus, and fracture properties of CNTs are an order of magnitude higher than most common composites used in civilian and military applications [5-8]. Moreover, CNTs reinforcement was proven to increase the toughness of the polymers and composite to absorb impact energy [9-12].

Most research to date had focused on using CNTs as a reinforcement or as a filler in a polymeric matrix by dispersing and perhaps subsequently aligning single- or multiwalled CNTs in the matrix $[13,14]$. Alignment and dispersion are critical factors that are difficult to control experimentally using oft-repeated mixing methods. CNTs embedded in a polymeric matrix form aggregates of them- selves that are not only poorly adhered to the matrix but also concentrate stresses, compromising the effect of the CNTs as reinforcement. Sonication [15] and calendaring [16] have been used to mitigate this problem, but these techniques are not effective beyond $\sim 3 \%$ CNTs weight fraction due to the formation of aggregates [17].

The extreme difficulty in uniformly dispersing CNTs in polymer matrices arises from the large surface area of CNTs [18]. Dispersion and extrusion techniques have been reported in the literature for producing CNTs composites [19]. The authors utilized high magnetic fields to process nanocomposites based on SWCNTs [14]. However, in both dispersion and extrusion techniques, producing uniform and well-dispersed carbon nanotubes composite is difficult because of the small amount of solid "powder" (carbon) compared with the large amount of liquid polymer (matrix) in early mixing stages. This often leads to phase separation due to the strong van der Waals forces between the CNTs themselves compared with that between CNTs and the polymer matrix [14]. 


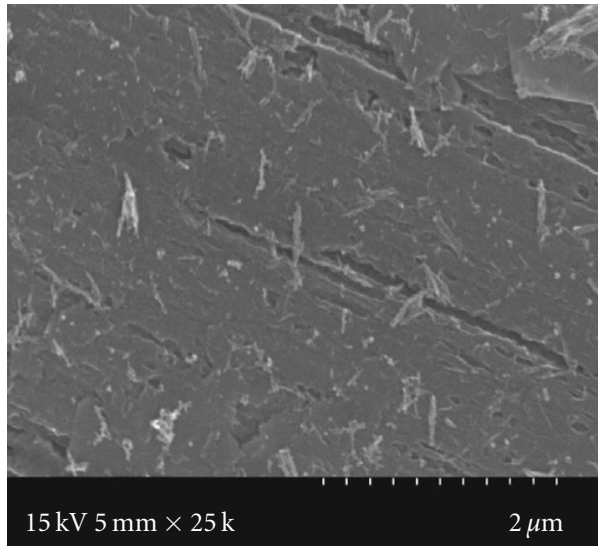

(a)

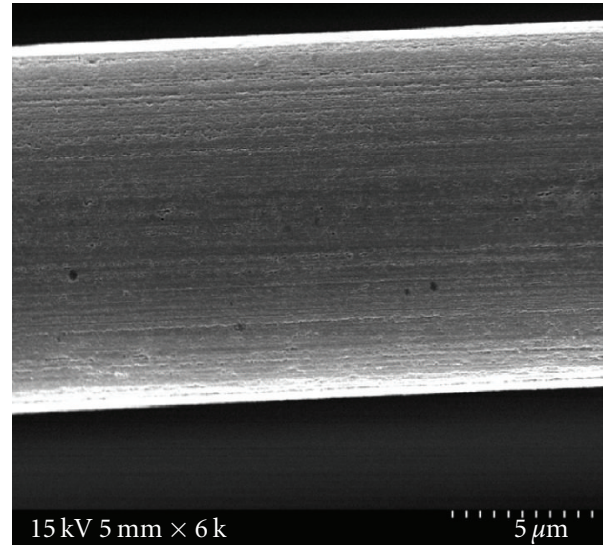

(b)

FIGURE 1: (a) SEM image of carbon fiber annealed at $500^{\circ} \mathrm{C}$ to remove sizing, (b) SEM image of carbon fiber cleaned by acetone and ethanol.

Alternatively, to eliminate the dispersion- related problems, CNTs can be controlled-grown in places where they are needed. CNTs can be grown over most substrates such as silicon, silica, and alumina $[17,20,21]$. CNTs growth on metallic substrates was also reported [22].

Recently, several investigations discussed the growth of CNTs on the surface of microscale graphitic and/or carbon structures. The growth of CNTs over carbon fiber encounters two obstacles: (i) the catalyst, if transition metal, can easily diffuse into the carbon substrate [23], and (ii) different phases of carbon can be formed on the graphitic substrate [24]. Similjanic et al. [25] had reported the growth of multiwall carbon nanotubes from ethylene on carbon paper by Ohmically heating the catalyst $(\mathrm{Co}-\mathrm{Ni})$. Silicate gel rich with catalytic metals was used to deposit the catalysts on carbon papers. Li et al. [26] utilized chemical vapor deposition (CVD) to control the growth of carbon nanotubes on graphite foil. The catalyst consisted of stainless steel (Fe: Cr: NI 70: 19: 11) deposited by DC magnetron sputtering. Similarly, Thostenson et al. [27] utilized magnetron sputtering to deposit stainless steel as catalyst to grow carbon nanotubes on carbon fiber using CVD with acetylene as the hydrocarbon. Alternatively, Zhu et al. [28] utilized incipient wetness to deposit iron nanoparticles on the surface of carbon fibers. The authors utilized thermal CVD with methane at $1000^{\circ} \mathrm{C}$ to grow the CNTs on the surface of carbon fibers. Other investigators achieved similar growth of CNTs over carbon fibers at milder thermal conditions [29] by utilizing $\mathrm{Ni}$ at catalyst and utilizing cyclopentadiene or benzene as the hydrocarbon. Beside the sputtering and incipient wetness, other investigators utilized electrochemical cells to deposit $\mathrm{Ni}$ catalyst on carbon fibers and used $\mathrm{CH}_{4}$ as precursor to grow CNTs on PAN and pitch-based carbon fibers [30].

Despite the numerous investigations cited earlier, there is no single investigation that discusses the effect of utilizing different techniques to deposit the catalyst on the nature of the CNTs growth on carbon substrate. The current study aims to offer a comparative investigation of the effect of the two leading techniques: DC magnetron sputtering and electrochemical deposition of the iron catalysts on the growth of CNTs over carbon fibers surfaces, under similar growth environments.

\section{Experimental}

\subsection{Catalyst Deposition}

2.1.1. Electrochemical Deposition. Electrochemical deposition of catalytic materials is a very complex problem that entails many parameters such as solution concentration, DC voltage, counter electrode material, time of deposition, and potential application scheme (continuous versus stepping potential, etc.). The long-term objective of this research is to grow "noncontinuous" film or "islands" of CNTs rather than uniform growth all over the carbon fiber. Continuous voltage electrochemical deposition will yield a uniform growth which is not desirable for the future application intended. This application entails manufacturing a hybrid composite. Having islands of growth rather than uniform growth will allow the epoxy matrix to "flow" and infiltrate inbetween the surface-grown CNTs. Continuous and uniform growth will not allow for the epoxy to "wet" in-between these nanostructures. Wetting these CNTs together with wetting the surface of the pitch carbon fiber will create the very desirable mechanical interlocking and anchoring mechanisms. Otherwise, if epoxy cannot anchor both the CNTs and the pitch fiber, then the original fiber will not carry any load; instead the CNTs/epoxy complex will do that. Such scenario defies the purpose of hybrid composites.

Pitch-based carbon fibers were used as substrate materials. These types of fibers are commonly used as reinforcements in traditional polymeric fibrous composites. Iron was chosen as the catalyst material since the gaseous precursor for CNTs synthesis was $\mathrm{C}_{2} \mathrm{H}_{4}$. A solution of $0.05 \mathrm{M} \mathrm{FeCl}_{3}$. $6 \mathrm{H}_{2} \mathrm{O}$ was prepared with deionized water and $\mathrm{pH}$ was adjusted to the 3.0 value by suitable $\mathrm{KOH}$ addition. To ensure the air removal, nitrogen gas was flown through the cell until no bubbles observed. A bundle of carbon fibers, first treated at $500^{\circ} \mathrm{C}$ for 90 minutes and then washed with acetone and ethyl alcohol to remove the sizing, were used 


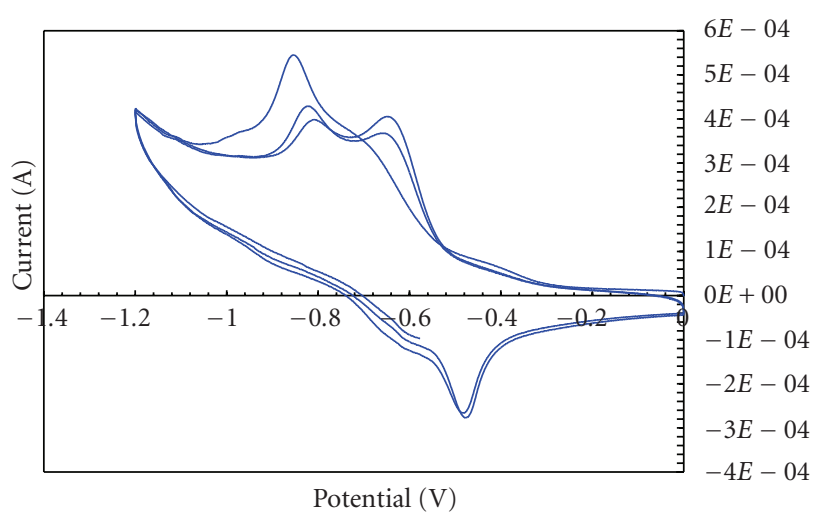

Figure 2: Cyclic Voltammogramm of $0.05 \mathrm{M} \mathrm{FeCl}_{3} \cdot 6 \mathrm{H}_{2} \mathrm{O} / \mathrm{KOH}$ $(\mathrm{pH}=3)$, with scan rate $50 \mathrm{mV} / \mathrm{s}$.

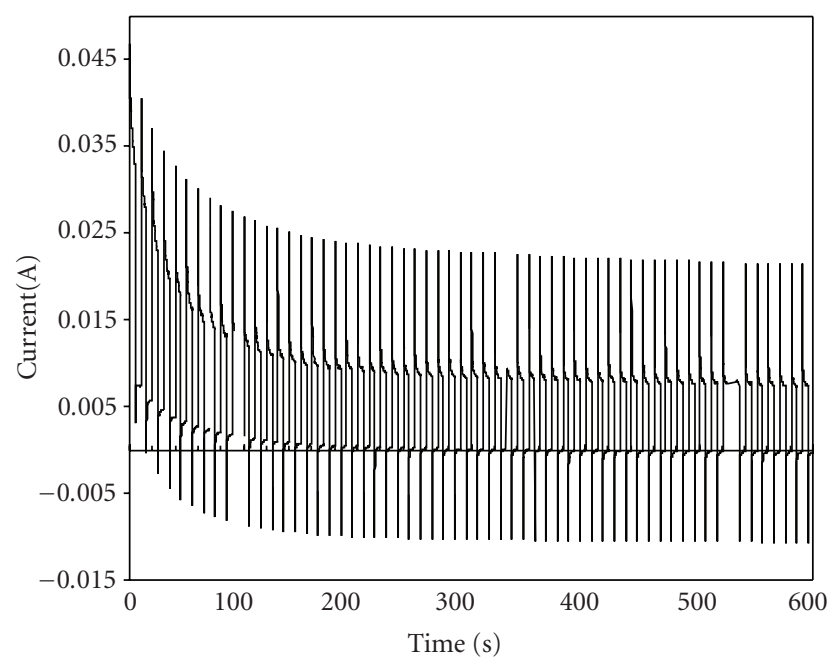

Figure 3: Current response throughout pulse voltammetry experiment for the $0.05 \mathrm{M} \mathrm{FeCl}_{3} .6 \mathrm{H}_{2} \mathrm{O} / \mathrm{KOH}(\mathrm{pH}=3.0)$ system with carbon fibers brush as working electrode.

as working electrode; see Figure 1(a) and 1(b). The bundles were arranged in a brush geometry being glued on one side to glass slide for mechanical support.

The counter electrode was a Pt wire and the reference electrode was saturated calomel electrode (SCE), saturated by $\mathrm{KOH}$, mounted in a Luggin capillary containing the iron solution prepared for the deposition. The voltammetric measurements and the potentiostatic experiments were performed by a model 760 series Potentiostat/Galvanostat, $\mathrm{CH}$ Instruments, Inc. Different deposition conditions were tested in order to optimize the dimension, morphology, and density of Fe clusters. Multipotential steps deemed to be the most efficient by applying a series of potential steps between 0 and $-0.7 \mathrm{~V}$ for duration of 5 seconds each step for a total of 5 minutes: 60 steps. For the sake of comparison we repeated the same experiment under $0.7 \mathrm{~V}$ but this time the voltage was applied continuously for 5 minutes. Finally, to investigate the effect of a higher voltage, the potential stepping and continuous potential deposition experiments were repeated using a $1.1 \mathrm{~V}$ potential.
2.1.2. Metal Sputtering. Iron was deposited on the surface of treated carbon fibers by DC magnetron sputtering of commercial target of high purity iron. The chamber was evacuated to a base pressure of $5 \times 10^{-6}$ Torr. The working pressure was maintained at $1 \times 10^{-3}$ Torr by introducing $\mathrm{Ar}$ gas, and the substrate temperature was maintained at $300^{\circ} \mathrm{C}$ during the sputtering. The sputtering power density was kept at $0.5 \mathrm{~W} / \mathrm{cm}^{2}$. Each carbon bundle was sputtered on both faces for 60 seconds at each face.

2.2. Chemical Vapor Deposition. A thermal CVD system was used for the carbon nanostructures growth. The CVD system is equipped with quartz tube of 1 -inch internal diameter. The samples were transferred in air and located in ceramic boats placed in the middle of the tube. Argon was flown into a CVD reactor in order to prevent oxidation of catalyst iron while raising the temperature. A mixture of $10 \% \mathrm{H}_{2}$ and $90 \% \mathrm{Ar}$ was flown in the reactor at $750^{\circ} \mathrm{C}$ for 10 minutes at $300 \mathrm{sccm}$ to reduce any oxide formed. $\mathrm{C}_{2} \mathrm{H}_{2}$ was introduced to the mix such that the composition is $10 \% \mathrm{H}, 5 \% \mathrm{C}_{2} \mathrm{H}_{2}$, and $85 \% \mathrm{Ar}$. The gases were introduced using separate flow controllers for 10 minutes at $300 \mathrm{sccm}$.

2.3. Characterization. Scanning Electron Microscopy (Hitachi S-4800 High-Resolution Scanning Electron Microscope (HRSEM) was employed to examine the deposited catalyst before the CNTs growth and also to investigate the purity and density of the CNTs after growth. High-resolution transmission electron microscope (TEM-JEOL 2010) was used to characterize the structure and diameter of the CNTs.

Raman spectra in the $100-2000 \mathrm{~cm}^{-1}$ region were obtained in a 180 degree back-scattering geometry on a confocal Raman microscope (Kaiser Optical). Sample excitation was through a $100 \mathrm{X}, 0.9 \mathrm{NA}$ microscope objective, using typically $1 \mathrm{~mW}$ of incident power at $514 \mathrm{~nm}$ from an argonion laser. Raman scattered light was collected through a fiber optic and dispersed (with approximately $5 \mathrm{~cm}^{-1}$ resolution) onto a CCD camera for detection. Typical integration times were 1 minute.

\section{Results and Discussion}

For the electrochemical deposition the electrolyte-electrode interface was studies to set suitable parameters for the deposition experiment. Cyclic voltammetry was utilized to set a suitable voltage and molarity of the electrolyte solution. Cyclic voltammetry has become a very popular technique for initial electrochemical studies of new systems and has proven very useful in obtaining information about fairly complicated electrode reactions. Voltametric curves, Figure 2, were obtained to collect general information about the iron electrodeposition process on the pitch carbon fibers; several peaks were observed at potential between -0.6 and $0.8 \mathrm{~V}$. Therefore, we choose $-0.7 \mathrm{~V}$ to be the voltage for the next electrochemical deposition. Upon deciding the working potential, pulse voltammetry was chosen to carry out the deposition of iron over the carbon fibers. Pulse voltammetry is preferred choice to deposit islands rather than continuous 


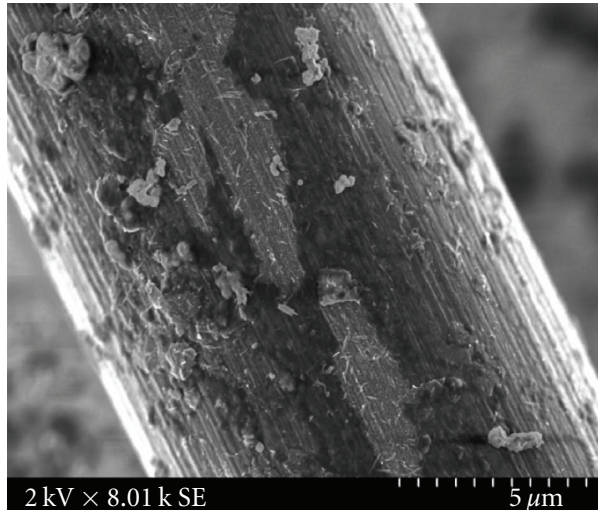

(a)

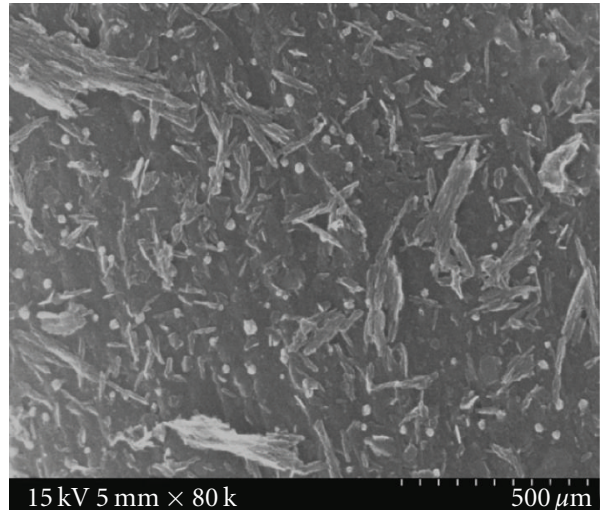

(b)

FIGURE 4: (a) Electrochemical deposition of iron on carbon fiber, and (b) HRSEM image of the deposited iron at $-0.7 \mathrm{~V}$ using multipotential stepping.

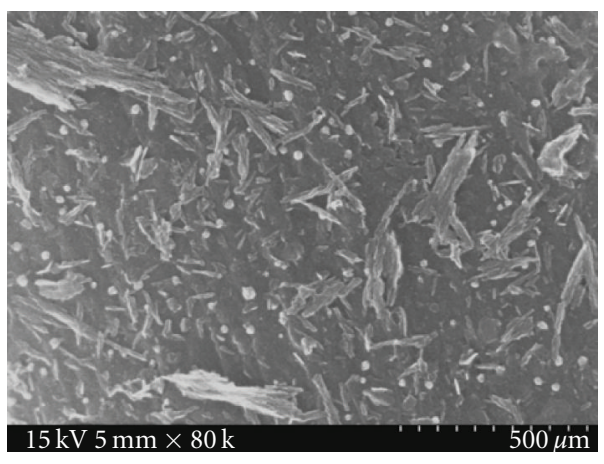

(a)

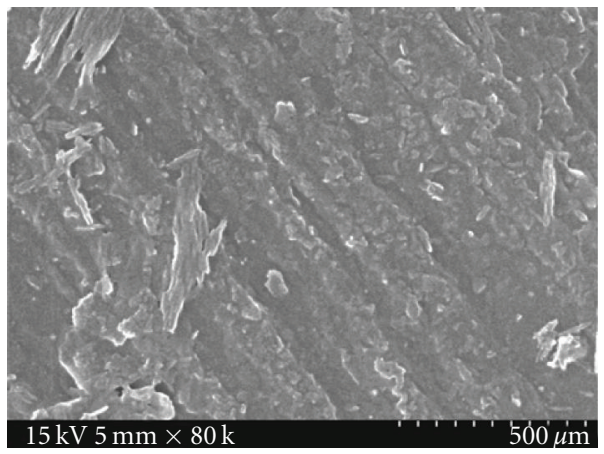

(c)

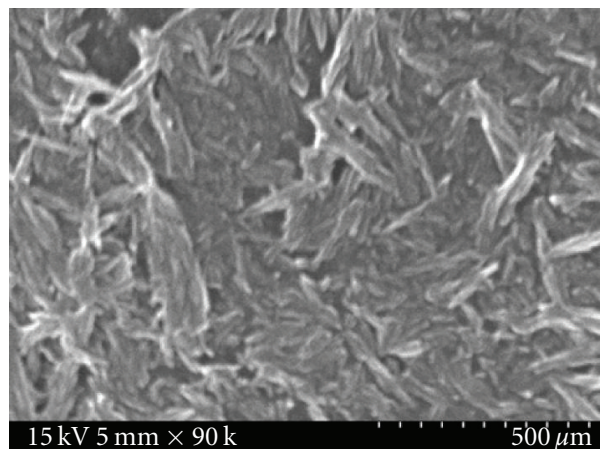

(b)

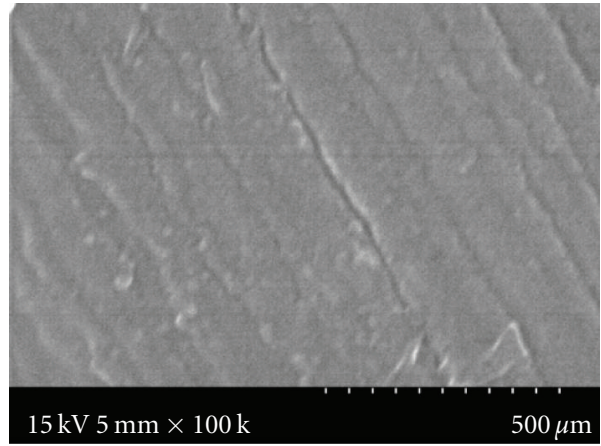

(d)

FIGURE 5: HRSEM of microstructures seen after electrochemical deposition of iron on carbon fiber, (a) at $-0.7 \mathrm{~V}$ using multipotential stepping, (b) using $-0.7 \mathrm{~V}$ continuous potential deposition, (c) using $-1.1 \mathrm{~V}$ using multipotential stepping, and (d) using - $1.1 \mathrm{~V}$ continuous potential deposition.

films of metals [31]. The potential between the working electrode and the reference electrode was changed as a pulse from an initial potential of 0 to an interlevel potential of -0.7 and remains at the interlevel potential for about 2 seconds; then it changes to the initial potential. The pulse is repeated, changing the final potential, and a constant difference is kept between the initial and the interlevel potential. The values of the current between the working electrode and auxiliary electrode before and after the pulses are sampled and their differences are plotted versus current; see Figure 3. The scan begins at potential of $-0.7 \mathrm{~V}$. Cathodic currents are upward. The time axis corresponds to the half-cycle index $m=5$ seconds.

On pitch fibers bundles used as electrode, iron clusters with various shapes and dimensions were observed; see Figure 4. The deposited iron compounds show great size variation from several microns, Figure 4(a), to nanoscale particles and rods, Figure 4(b). It is also observable at both 


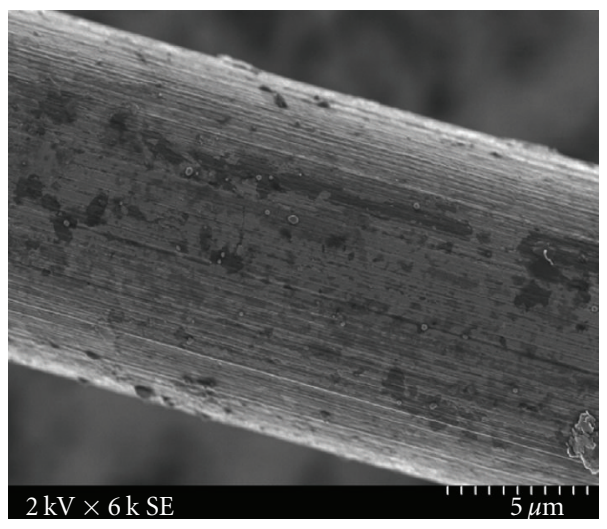

(a)

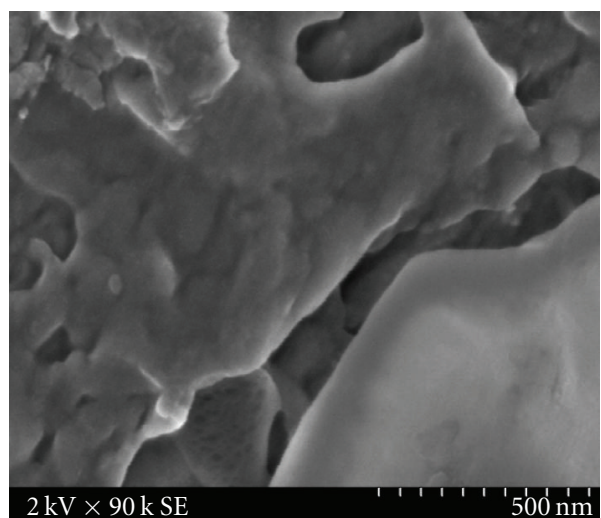

(b)

FIgURE 6: (a) Iron deposition using DC sputtering method. HRSEM image of the sputtered iron films.

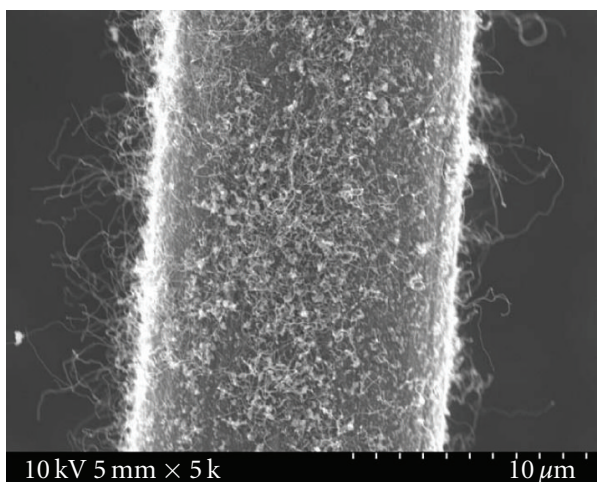

(a)

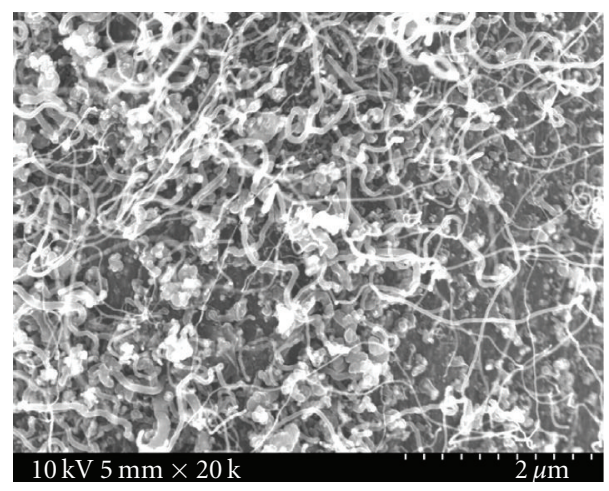

(b)

FIGURE 7: (a) SEM image of CNTs growth on carbon fiber using the iron DC sputtering technique, and (b) close-up image of the CNTs grown via CVD using iron evaporation deposition.

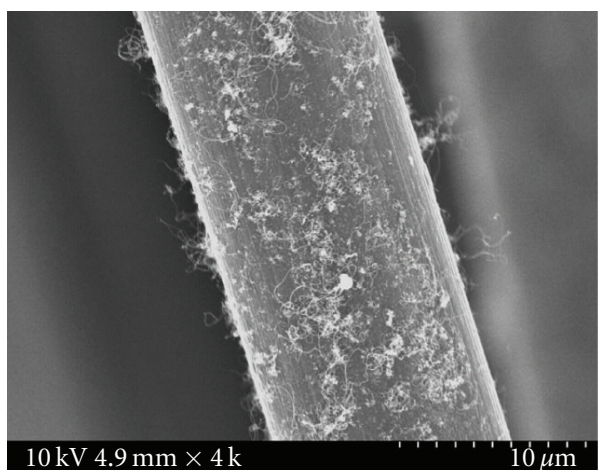

(a)

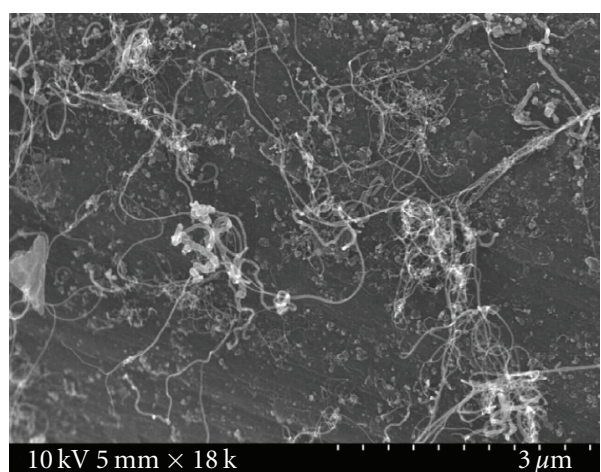

(b)

FIGURE 8: (a) SEM image of CNTs growth on carbon fiber using the electrochemical deposition of iron catalyst and (b) close up image of CNTs grown using electrochemical deposition. 


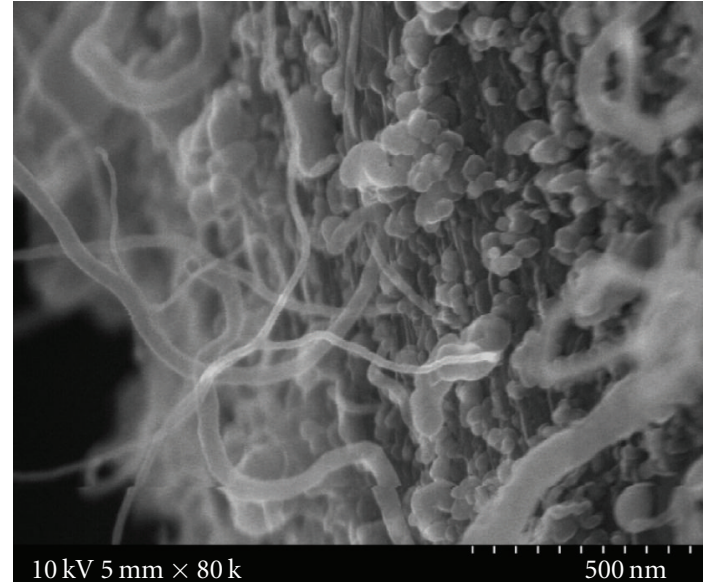

FIGURE 9: SEM image of CNTs grown on pitch carbon fiber. The continuous nature of the deposited catalyst film is not observed; instead, nanoscale particles or Fe/C compounds are observed.

scales that the iron deposition took the form of islands rather than continuous films. The high surface coverage can be attributed to the parametric setup for the molarities of the electrolyte solution, the working potential, and the conductive nature of pitch fibers.

Figure 5 reveals that applying continuous potential rather than potential stepping increased the deposition density and surface coverage of the iron on the carbon fiber surface. Furthermore, several nanostructures $(<100 \mathrm{~nm}$, Figure 5(a)) have disappeared leading to the conclusion of agglomeration under such continuous potential deposition, Figure 5(b). Finally upon applying $-1.1 \mathrm{~V}$ stepping potential (Figure 5(c)) fewer deposition was observed compared to the $-0.7 \mathrm{~V}$, and almost no deposition was observed when the $-1.1 \mathrm{~V}$ potential was applied continuously, Figure 5(d). Thus, the $-0.7 \mathrm{~V}$ was more favorable deposition potential and we limited the next synthesis and characterization steps for samples with catalytic iron deposited under $-0.7 \mathrm{~V}$ stepping potential.

On the contrary, DC magnetron sputtering technique yielded more continuous and uniform deposition of iron films, Figure 6. Nanofeatures could not be observed in the deposited catalytic iron films, an indication of considerable thickness. Figure 7 shows SEM images of CNTs growth on the pitch fiber surface with catalytic iron deposited via DC sputtering while Figure 8 shows CNTs growth when iron is deposited using the pulse voltammetry technique.

The results in Figures 7 and 8 suggest that both techniques are successful to grow CNTs on the carbon fiber surfaces. However the iron sputtering shows more dense growth due to the uniform distribution of the iron catalyst using this technique; evidently a lower cluster/film density of the catalyst corresponds to a less dense carbon nanotubes growth. Another interesting feature is that the continuous film of catalytic iron, shown in Figure 7, was shattered into particles upon the reduction and growth stages, Figure 9.

Moreover, TEM analysis revealed that different types of carbon nanostructures were synthesized as shown in

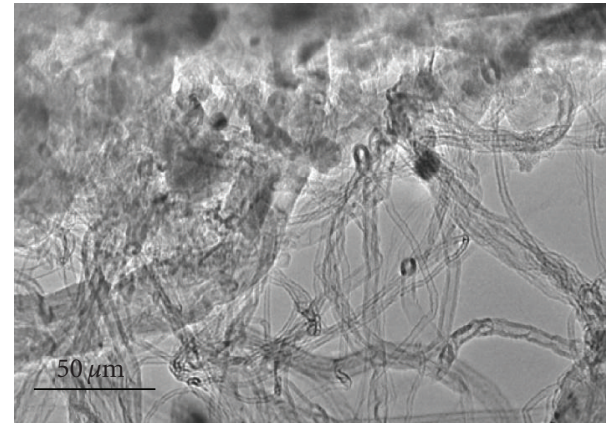

(a)

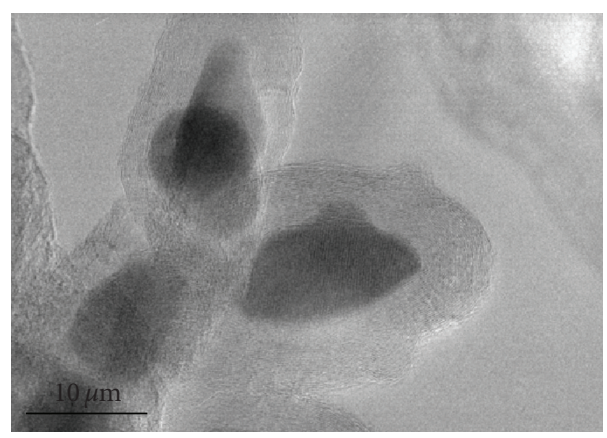

(b)

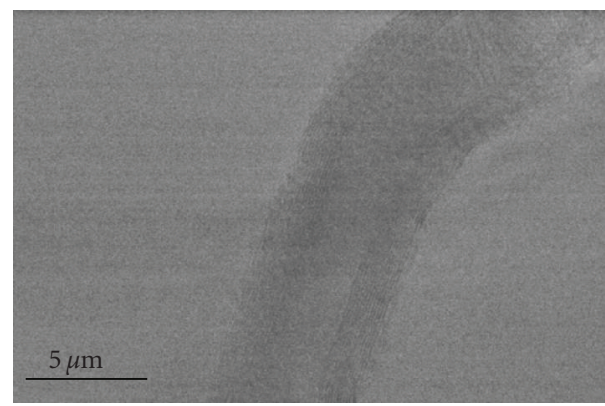

(c)

FiguRE 10: TEM images of carbon nanostructures observed for samples with iron deposition carried out via electrochemical deposition.

Figures 10 and 11. Multiwall carbon nanotubes were the dominant feature of the growth nanostructures regardless of the catalyst deposition method, Figures 10(a)-11(a). One notable feature is the purity of the generated MWCNT; not many iron particles are observed at the end of MWCNT tips. However, the electrochemical deposition yielded MWCNT with smaller external diameter $(<15 \mathrm{~nm})$ than that for the MWCNT grown via the DC sputtered iron $(>25 \mathrm{~nm})$. The second species of nanostructure comprise of the iron particles encapsulated within several graphitic shells as shown in Figures 10(b) and 11(b). This indicates that iron particles that have been formed during the reduction step are too large to generate filamentous carbon; instead they remain active and get surrounded by layers of graphitic materials. This observation was cited by other investigators, when using 


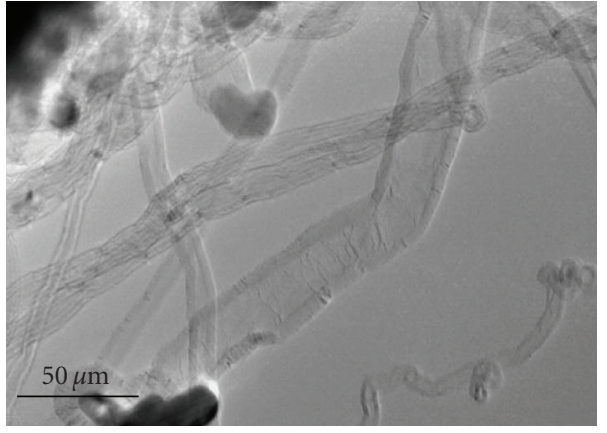

(a)

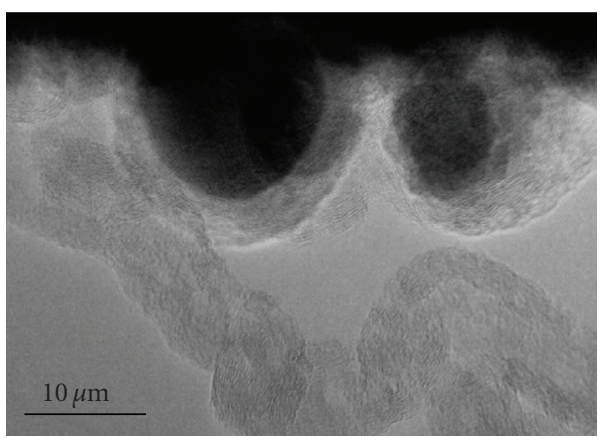

(b)

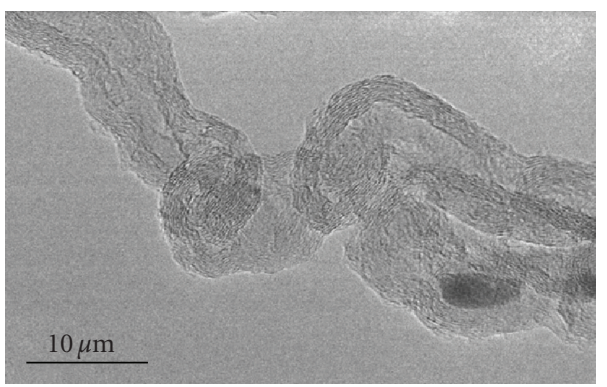

(c)

FIGURE 11: TEM images of carbon nanostructures observed for samples with iron deposition carried out via DC magnetron sputtering.

other catalysts such as $\mathrm{Ni}$ and $\mathrm{Co}$ [32]. Consulting the TEM images, it is apparent that the majority of the grown MWCNTs have diameters within $10 \mathrm{~nm}$. From the close up TEM images, Figures 10(c)-11(c), it seems that no traces of amorphous carbon can be found on the inner or on the outer walls of the tubes.

Finally, Raman spectra analysis of the neat carbon fibers, carbon fibers with catalysts, and carbon fibers with surface grown MWCNTs are presented in Figure 12. Raman spectra analysis was performed in the $100-2500 \mathrm{~cm}^{-1}$ spectral region. The spectra for the carbon fiber spectra show mainly two Raman bands at $1350 \mathrm{~cm}^{-1}$ (D band) and $1580 \mathrm{~cm}^{-1}(\mathrm{G}$ band). The $G$ band typically observed in single crystals of graphite and assigned to a doubly degenerate deformation vibration of the hexagonal ring while the $\mathrm{D}$ band is produced by the defect-inducing vibration mode, that is, the noncrystalline carbon-specific absorption band [33].

Having the iron catalyst deposited on the carbon fiber did not show significant difference among the spectra, Figures 12(b) and 12(c). For Figures 12(d) and 12(e), the decrease in the intensity ratio of $D$ band to $G$ band (I (D)/I (G)) was slightly higher for the carbon fibers with MWCNTs grown by DC sputtering of iron. This reveals that the degree of crystalline perfection of the MWCNTs grown using DC sputtering iron is slightly higher than that of MWCNTs grown using electrochemical deposition of iron. Also the width of the $\mathrm{D}$ peak for that sample is narrower than that for the sample where electrochemical deposition was utilized to deposit the iron. This may be an indication of a high degree of order in the sample and/or less amorphous impurities.

\section{Conclusions}

We presented the results of a comparative study to grow CNTs on pitch-based carbon fiber surfaces using DC magnetron sputtering of iron and electrochemical deposition of the iron catalysts. A bundle of carbon fibers was treated at $500^{\circ} \mathrm{C}$ for 90 minutes and then washed with acetone and ethyl alcohol to remove the sizing. For electrochemical deposition, $\mathrm{C}_{2} \mathrm{H}_{4}$ was used as the gaseous precursor for CNTs synthesis and Iron was chosen as the catalyst material. Cyclic voltammetry was utilized to set a suitable voltage and molarity of the electrolyte solution. Pulse voltammetry was chosen to deposit of iron over the carbon fibers to enable depositing islands rather than a continuous film. In metal sputtering method, iron was deposited on the surface of treated carbon fibers by DC magnetron sputtering of commercial target of high purity iron. Carbon nanostructures growth was performed using a thermal CVD system. Characterization for comparison between both techniques was done using SEM, TEM, and Raman spectra analysis.

Characterization methods showed that both techniques were successful to grow CNTs on the carbon fiber surfaces. However, the iron sputtering shows denser growth due to the uniform distribution of the iron catalyst. While the electrochemical deposition resulted in iron deposition in the form of islands, DC magnetron sputtering technique yielded a continuous and uniform deposition of iron films. TEM images proved that both techniques enabled producing multiwall carbon nanotubes with significant purity regardless of the catalyst deposition method. The results of Raman spectra analysis revealed that MWCNTs grown using DC sputtering of iron have a little higher degree of crystalline perfection than those MWCNTs grown using electrochemical deposition of iron. The ease of the DC sputtering of iron, less process parameters compared to electrochemical deposition, suggests DC iron sputtering as a leading alternative to produce new hybrid carbon fibercarbon nanotubes structures that will enable new types of structural composites. 


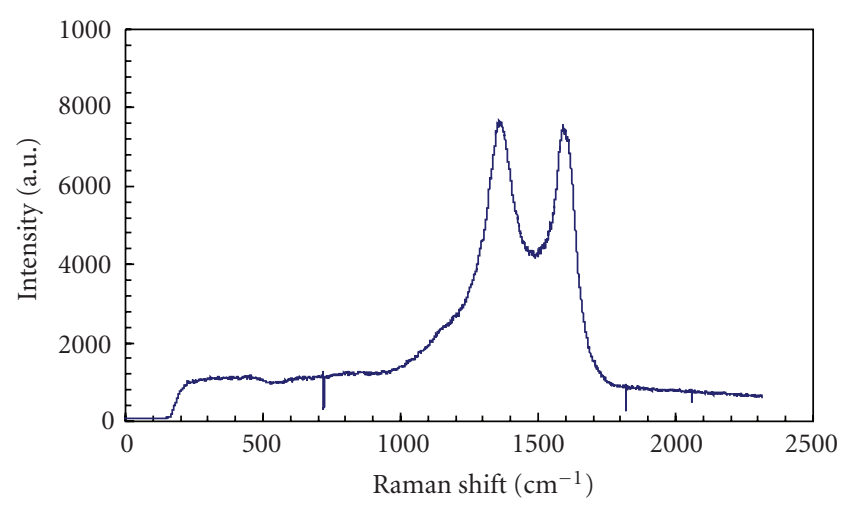

(a)

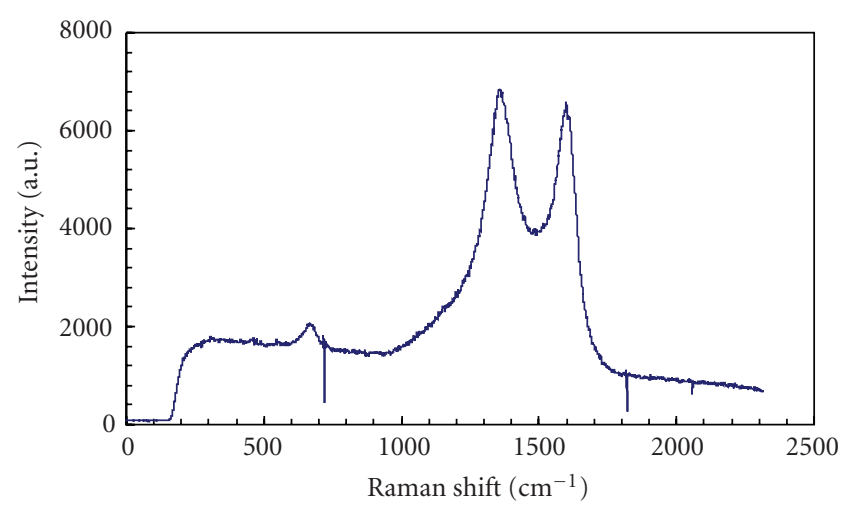

(c)

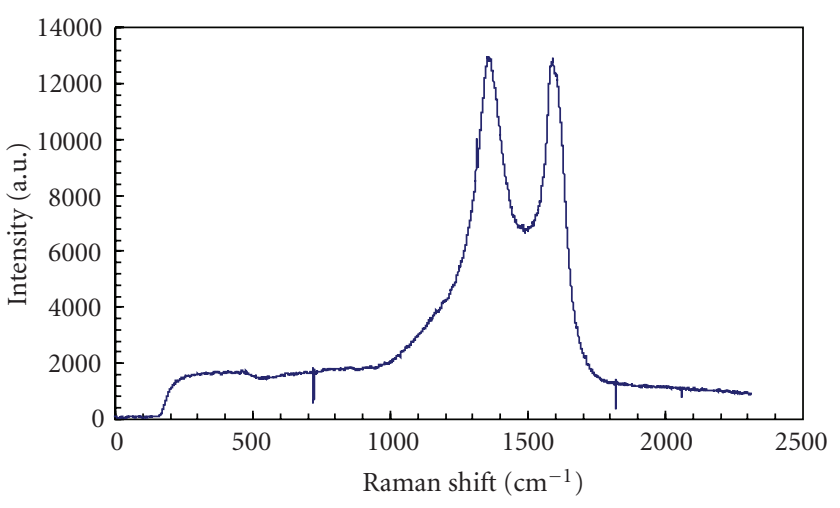

(b)

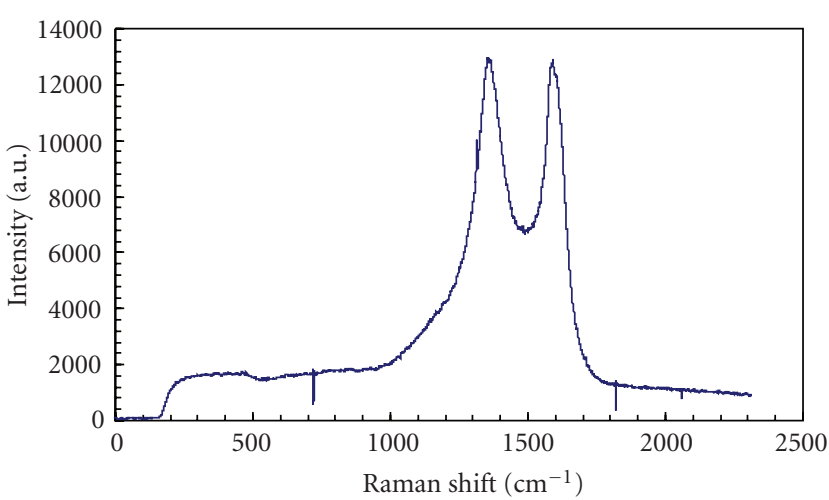

(d)

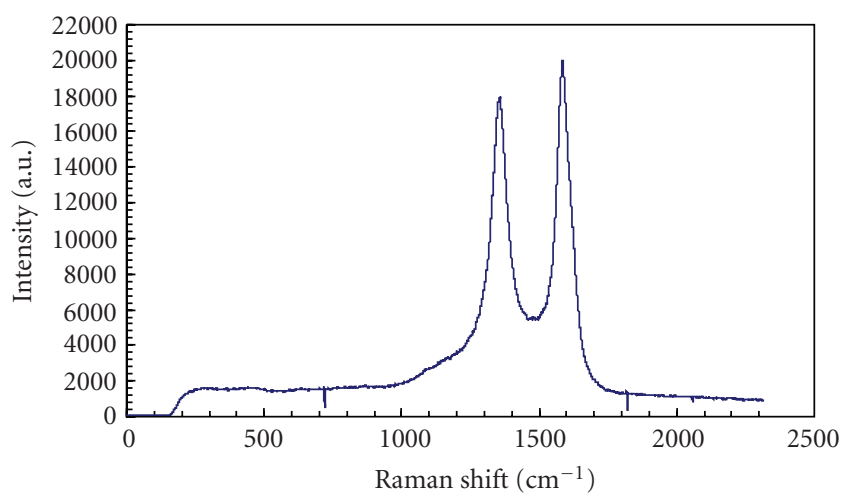

(e)

FIGURE 12: Raman spectrum for (a) carbon fiber with removed sizing, (b) carbon fiber with iron deposition via electrochemical deposition, (c) carbon fiber with iron deposition via Dc magnetron sputtering, (d) carbon fiber with surface grown MWCNTs (iron was deposited using electrochemical multipotential, and (e) carbon fiber with surface grown MWCNTs (iron was deposited using DC magnetron sputtering).

\section{Acknowledgments}

This work has been supported by several funding agencies including the National Science Foundation (NSF) Awards nos. CMMI-0800249 and CMMI 0846589, Defense Threat Reduction Agency (DTRA) Grant nos. HDTRA1-08-1-0017 P00001, and the America Society of Engineering Education (ASEE), Air Force Research Laboratory (AFRL), Summer Faculty Fellowship Program (SFFP) to Dr. Al-Haik. The authors gratefully acknowledge this support.

\section{References}

[1] S. Iijima, "Helical microtubules of graphitic carbon," Nature, vol. 354, no. 6348, pp. 56-58, 1991.

[2] A. G. Rinzler, J. Liu, H. Dai, et al., "Large-scale purification of single-wall carbon nanotubes: process, product, and characterization," Applied Physics A, vol. 67, no. 1, pp. 29-37, 1998.

[3] D. Dietzel, M. Faucher, A. Iaia, et al., "Analysis of mechanical properties of single wall carbon nanotubes fixed at a tip apex by atomic force microscopy," Nanotechnology, vol. 16, no. 3, pp. S73-S78, 2005. 
[4] J. Bernholc, D. Brenner, M. B. Nardelli, V. Meunier, and C. Roland, "Mechanical and electrical properties of nanotubes," Annual Review of Materials Science, vol. 32, pp. 347-375, 2002.

[5] ASM, Composites Handbook, ASM International, Materials Park, Ohio, USA, 1987.

[6] S. R. Lampman, Ed., Fatigue and Fracture Handbook, ASM International, Materials Park, Ohio, USA, 1996.

[7] ASM, Metals Handbook Desk Edition, ASM International, Materials Park, Ohio, USA, 1998.

[8] E. T. Thostenson and T.-W. Chou, "Aligned multi-walled carbon nanotube-reinforced composites: processing and mechanical characterization," Journal of Physics D, vol. 35, no. 16, pp. L77-L80, 2002.

[9] R. E. Gorga and R. E. Cohen, "Toughness enhancements in poly(methyl methacrylate) by addition of oriented multiwall carbon nanotubes," Journal of Polymer Science, Part B, vol. 42, no. 14, pp. 2690-2702, 2004.

[10] B. K. Satapathy, R. Weidisch, P. Pötschke, and A. Janke, "Crack toughness behaviour of multiwalled carbon nanotube (MWNT)/polycarbonate nanocomposites," Macromolecular Rapid Communications, vol. 26, no. 15, pp. 1246-1252, 2005.

[11] H. Zhang and Z. Zhang, "Impact behaviour of polypropylene filled with multi-walled carbon nanotubes," European Polymer Journal, vol. 43, no. 8, pp. 3197-3207, 2007.

[12] H. Miyagawa and L. T. Drzal, "Thermo-physical and impact properties of epoxy nanocomposites reinforced by single-wall carbon nanotubes," Polymer, vol. 45, no. 15, pp. 5163-5170, 2004.

[13] E. S. Choi, J. S. Brooks, D. L. Eaton, et al., "Enhancement of thermal and electrical properties of carbon nanotube polymer composites by magnetic field processing," Journal of Applied Physics, vol. 94, no. 9, pp. 6034-6039, 2003.

[14] H. Garmestani, M. S. Al-Haik, K. Dahmen, et al., "Polymermediated alignment of carbon nanotubes under high magnetic fields," Advanced Materials, vol. 15, no. 22, pp. 1918 1921, 2003.

[15] L. Jin, C. Bower, and O. Zhou, "Alignment of carbon nanotubes in a polymer matrix by mechanical stretching," Applied Physics Letters, vol. 73, no. 9, pp. 1197-1199, 1998.

[16] F. H. Gojny, M. H. G. Wichmann, U. Köpke, B. Fiedler, and K. Schulte, "Carbon nanotube-reinforced epoxy-composites: enhanced stiffness and fracture toughness at low nanotube content," Composites Science and Technology, vol. 64, no. 15, pp. 2363-2371, 2004.

[17] E. Garcia, B. L. Wardle, R. G. deVillori, et al., "Aligned carbon nanotube reinforcement of advanced composite ply interfaces," in Proceedings of the 49th AIAA/ASME/ASCE/AHS/ASC Structures, Structural Dynamics, and Materials Conference, Schaumburg, Ill, USA, 2008.

[18] Z. Xia, L. Riester, W. A. Curtin, et al., "Direct observation of toughening mechanisms in carbon nanotube ceramic matrix composites," Acta Materialia, vol. 52, no. 4, pp. 931-944, 2004.

[19] Y.-L. Li, I. A. Kinloch, and A. H. Windle, "Direct spinning of carbon nanotube fibers from chemical vapor deposition synthesis," Science, vol. 304, no. 5668, pp. 276-278, 2004.

[20] E. J. García, A. J. Hart, and B. L. Wardle, "Long carbon nanotubes grown on the surface of fibers for hybrid composites," AIAA Journal, vol. 46, no. 6, pp. 1405-1412, 2008.

[21] N. Yamamoto and B. L. Wardl, "Electrical and thermal properties of hybrid woven composites reinforced with aligned carbon nanotubes," in Proceedings of the 49th AIAA/ASME/ASCE/AHS/ASC Structures, Structural Dynamics, and Materials Conference, Schaumburg, Ill, USA, April 2008.
[22] C. Emmenegger, P. Mauron, A. Züttel, et al., "Carbon nanotube synthesized on metallic substrates," Applied Surface Science, vol. 162, pp. 452-456, 2000.

[23] Z.-G. Zhao, L.-J. Ci, H.-M. Cheng, and J.-B. Bai, "The growth of multi-walled carbon nanotubes with different morphologies on carbon fibers," Carbon, vol. 43, no. 3, pp. 663-665, 2005.

[24] S. Zhu, C.-H. Su, S. L. Lehoczky, I. Muntele, and D. Ila, "Carbon nanotube growth on carbon fibers," Diamond and Related Materials, vol. 12, no. 10-11, pp. 1825-1828, 2003.

[25] O. Smiljanic, T. Dellero, A. Serventi, et al., "Growth of carbon nanotubes on Ohmically heated carbon paper," Chemical Physics Letters, vol. 342, no. 5-6, pp. 503-509, 2001.

[26] W. Z. Li, D. Z. Wang, S. X. Yang, J. G. Wen, and Z. F. Ren, "Controlled growth of carbon nanotubes on graphite foil by chemical vapor deposition," Chemical Physics Letters, vol. 335, no. 3-4, pp. 141-149, 2001.

[27] E. T. Thostenson, W. Z. Li, D. Z. Wang, Z. F. Ren, and T. W. Chou, "Carbon nanotube/carbon fiber hybrid multiscale composites," Journal of Applied Physics, vol. 91, no. 9, p. 6034, 2002.

[28] S. Zhu, C.-H. Su, S. L. Lehoczky, I. Muntele, and D. Ila, "Carbon nanotube growth on carbon fibers," Diamond and Related Materials, vol. 12, no. 10-11, pp. 1825-1828, 2003.

[29] K. Otsuka, Y. Abe, N. Kanai, Y. Kobayashi, S. Takenaka, and E. Tanabe, "Synthesis of carbon nanotubes on Ni/carbon-fiber catalysts under mild conditions," Carbon, vol. 42, no. 4, pp. 727-736, 2004.

[30] T. D. Makris, R. Giorgi, N. Lisi, et al., "Carbon nanotube growth on PAN- and pitch-based carbon fibres by HFCVD," Fullerenes Nanotubes and Carbon Nanostructures, vol. 13, supplement 1, pp. 383-392, 2005.

[31] A. J. Bard and L. R. Faulkner, Electrochemical Methods Fundamentals and Applications, John Wiley \& Sons, New York, NY, USA, 2nd edition, 2001.

[32] O. Smiljanic, T. Dellero, A. Serventi, et al., "Growth of carbon nanotubes on Ohmically heated carbon paper," Chemical Physics Letters, vol. 342, no. 5-6, pp. 503-509, 2001.

[33] T.-H. Ko, "Raman spectrum of modified PAN-based carbon fibers during graphitization," Journal of Applied Polymer Science, vol. 59, no. 4, pp. 577-580, 1996. 

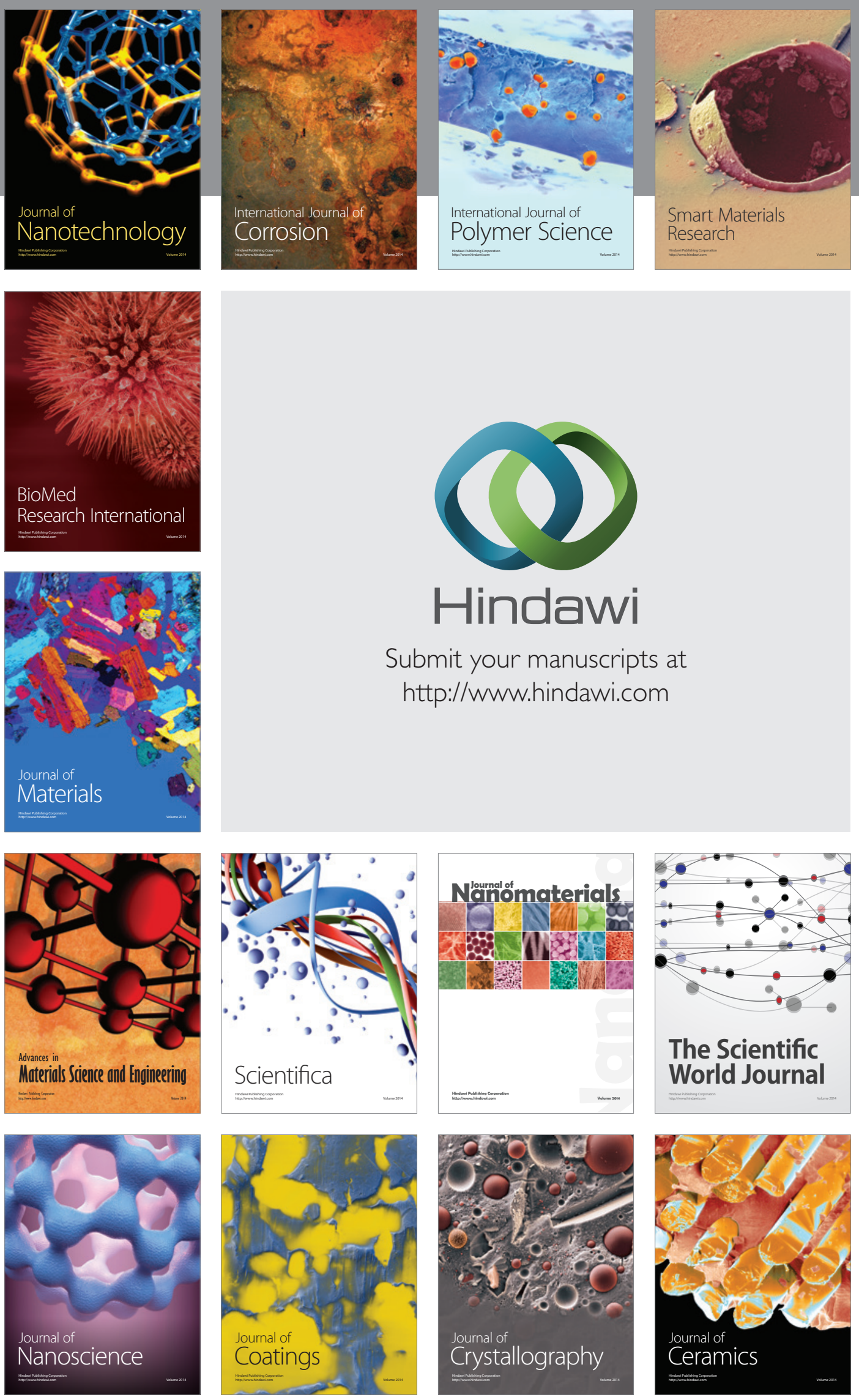

The Scientific World Journal

Submit your manuscripts at

http://www.hindawi.com

\section{World Journal}

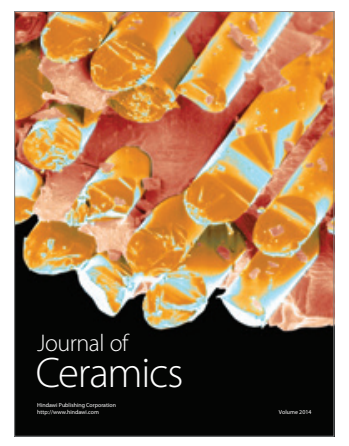

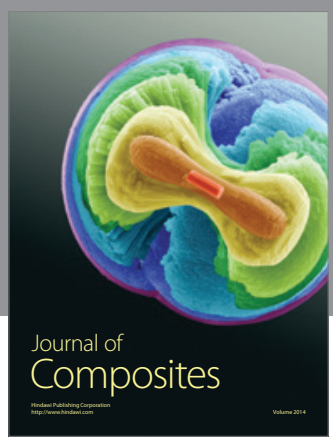
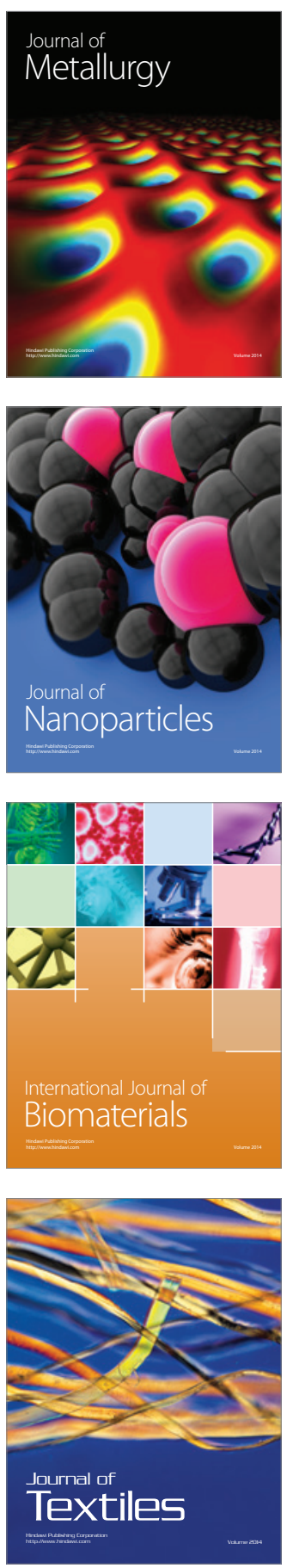